\title{
DIETARY MANIPULATION TO INCREASE THE CONCENTRATION OF N-3 FATTY ACIDS IN MILK FAT
}

\author{
SUli, A. ${ }^{*}{ }^{*}$ - GARIPOGLU, A. V. ${ }^{2}-$ CSAPO, J. $^{3}-$ BERI, B. ${ }^{3}-$ VARGANE, V. E. ${ }^{4}-$ MikONE, J. E. ${ }^{1}$ \\ ${ }^{1}$ Institute of Animal Sciences and Wildlife Management, Faculty of Agriculture, University of \\ Szeged, 15 Andrassy Rd., Hodmezovasarhely 6800, Hungary \\ ${ }^{2}$ Department of Animal Science, Faculty of Agriculture, Ondokuz Mayis University, Atakum, \\ Kurupelit Kampüsü, Samsun 55100, Turkey \\ ${ }^{3}$ Faculty of Agriculture and Food Sciences and Environmental Management, University of \\ Debrecen, 138 Boszormenyi Rd., Debrecen 4032, Hungary \\ ${ }^{4}$ Faculty of Agriculture and Environmental Sciences, Institute of Physiology, Biocehmistry and \\ Animal Health, University of Kaposvar, 40 Guba S. Rd., Kaposvar 7400, Hungary \\ *Corresponding author \\ e-mail: suli@mgk.u-szeged.hu; phone: +36-70-604-3922 \\ (Received $27^{\text {th }}$ Sep 2017; accepted $11^{\text {th }}$ Jan 2018)
}

\begin{abstract}
Linseed is an excellent source of PUFA, especially linolenic acid (18:3n-3), but it is not commonly used in dairy diet in Hungary. Aim of this study was to investigate the effect of the supplemented whole linseed on fatty acid profile of milk fat, with particular reference to health promoting components ( $\alpha$-linolenic acid). A total of thirty multiparous Holstein cows were used in two dairy farms to determine the effect of feeding whole linseed rich in linolenic (C18:3) fatty acids on fatty acid composition of milk fat. The experiment was conducted on two large-scale dairy farms located in HajdúBihar County (referred to as farm " $\mathrm{A}$ " and "B"). Fifteen multiparous Holstein-Friesian (165 average days in milk) on farm A and fifteen multiparous Holstein-Friesian (200 average days in milk) on farm B were randomly allocated to treatment groups to investigate the effect of whole linseed supplementation on the composition of fatty acids of milk fat. The group on farm A and B fed TMR based maize silage without whole linseed during the control-period. In the experimental-period the cows received the same TMR on both farms, but it was supplemented with $2.60 \% \mathrm{DM}$ of whole linseed on farm $\mathrm{A}$, and $2.16 \% \mathrm{DM}$ of whole linseed on farm B. The experimental period was four weeks in both farms. The supplementation of whole linseed had no effect $(\mathrm{P}>0.05)$ on the short chain saturated fatty acid (SFA), and most of the medium chain saturated fatty acid. During the trial the oleic acid (18:1c) content in milk fat significantly increased (21.33\% at the start, $24.71 \%$ after 2 weeks and $22.51 \%$ after 4 weeks on farm B, respectively). The proportion of $\alpha$-linolenic acid (18:3n-3) increased $(\mathrm{P}>0.05)$ during the experimental period compared to the control period $(0.23 \%$ at the start, $0.58 \%$ after 2 weeks and $0.59 \%$ after 4 weeks on farm B). The concentration of long-chain polyunsaturated fatty acids (eicosapentaenoic acid and docosapentaenoic acid) significantly increased in milk fat after 4 weeks on both farms. The $n-6 / n-3$ ratio narrowed from 13.52:1 to 3.83:1 and 3.69:1 on farm B, respectively, but this result was not significant. This study concluded that dietary supplementation of whole linseed decreased the proportion of some SFA and increased the proportion of some MUFA and PUFA.
\end{abstract}

Keywords: dairy cattle, whole linseed, milk fatty acid composition, $\alpha$-linolenic acid

\section{Introduction}

Nowadays, the food is not just a nutrition source in the human diet; rather a valueadded product having additional features. The relationship between dietary fat intake and the incidence of lifestyle diseases, particularly coronary heart disease, is well established and has contributed to the development of specific government health 
recommendations for food components, especially fats (Simopoulus, 2001). As consumer expectations regarding milk and dairy products have changed in Hungary, they suffer from a negative health image (related to the nature of their lipid fraction). The predominant fatty acids in milk are short-, and medium-chain saturated fatty acids (mainly 12:0, 14:0 and 16:0). In Hungary, just like in most European countries, preserved (fermented) forages and a variety of roughages provide the basis of ruminant feed. The fatty acid (FA) composition of cow's milk has become less favourable to human health due to changed feeding and management practices, notably higher proportions of concentrates and silages in diets with less grazing (Elgersma et al., 2006). Although there are differences in the fatty acid composition of milk fat from cows consuming warm season pasture species compared with milk from cows consuming a total mixed ration (White et al., 2001), there are several other factors influencing the behaviour of the animal on rangeland, for example weather (Halasz et al., 2016), and through this the choice of pasture species.

The new economic conditions of dairy production, especially in the EU, have resulted in pressure to limit milk fat content and optimize its fatty acid composition (Demeyer and Doreau, 1999).

The positive influence of n-3 polyunsaturated fatty acids (PUFA) on cardiovascular illnesses suggests that it would be of benefit to increase such fatty acids in milk (Kinsella, 1991). Essential fatty acids, both n-6 (linoleic acid) and n-3 ( $\alpha$-linolenic acid) have been part of our diet since the very beginning of human life. A balanced intake of both n-6 and n-3 fatty acids is essential for health. This ratio should decrease from the current $20-30 / 1$ to less than $4 / 1$ to reduce the potential risk coronary heart disease (Simopoulus, 1999). Extensive research has been conducted in order to modify the fatty acid composition of milk fat to reach the expectations towards functional foods. Optimal supplementing of dairy cows' ration increases the proportion of polyunsaturated fatty acids (PUFA) and decreases the proportion of saturated fatty acids (SFA) in milk fat. Feeding oilseeds to lactating dairy cows is just one of the several methods to change the proportion of fatty acid composition of milk fat (Petit, 2003).

Linseed is an excellent source of PUFA, especially $\alpha$-linolenic acid (18:3n-3), but it is not commonly used in dairy diet in Hungary. Moreover, feeding whole oilseeds would be a less expensive option compared with treating oilseeds with casein and formaldehyde as the latter requires more specialized equipment (Petit, 2003). Feeding of protected flaxseed oil or whole linseed to dairy cows could increase the n-3 fatty acid content in milk fat (Moallem, 2009).

Animal products with increased contents of n-3 fatty acid might help to solve of low n-3 fatty acid consumption of the Hungarian population (Perédi, 2002). A number of studies consider the use of oilseeds and/or their by-products and other high PUFAcontaining lipids as perspective method in animal nutrition (Murphy et al., 1995a, b; Petit, 2002; Livingstone et al., 2015; Poti et al., 2015; Caroprese et al., 2017).

We hypothesized that the fatty acid composition of milk fat can be improved when the animals are fed with above $2 \%$ DM whole linseed supplemented diet.

The objective of this study was to investigate the possible changes in the fatty acid composition of milk fat by feeding whole linseed to dairy cows. 


\section{Material and methods}

The experiment was conducted in two large-scale dairy farms located in Hajdú-Bihar County, Hungary. Hereafter, these farms will be referred to as " $A$ " and "B". Fifteen multiparous (seven cows in second parity and eight cows in third parity) HolsteinFriesian (165 average days in milk) on farm A and fifteen multiparous (six cows in second parity and nine cows in third parity) Holstein-Friesian (200 average days in milk) on farm B were randomly allocated to treatment groups. The average daily milk yield level in the treatment group was $40 \mathrm{~kg}$-s on farm A and it was $38 \mathrm{~kg}$-s on farm B. During the control-period the cows were fed TMR (total mixed ration) based maize silage without whole linseed three times a day. In the experimental period the cows were fed TMR based maize silage with additional whole linseed three times a day. As Table 1 shows the whole linseed supplementation of the daily ration was $2.60 \% \mathrm{DM}$ that equals $1.5 \mathrm{~kg} /$ day/cow on farm $\mathrm{A}$ and on farm B the whole linseed supplementation was $2.16 \% \mathrm{DM}$ of the daily ration that equals $1.0 \mathrm{~kg} /$ day/cow. The maize silage based rations had similar net energy content (Table 1). The experimental period was four weeks. During this time, milk samples were taken three times from each cow: at the start of the experiment, after two weeks and after four weeks. Sampling was scheduled according to the milking order every time. Samples were taken at the same milking period. Individual milk samples were collected twice a day during the experimental period. Milk samples were frozen and stored until further analysis.

Table 1. Ingredient composition and chemical composition of TMR (\% of DM basis)

\begin{tabular}{c|c|c}
\hline Ingredients & TMR (farm A) & TMR (farm B) \\
\hline Corn silage & 41.45 & 44.64 \\
\hline Lucerne haylage & 11.05 & 6.69 \\
\hline Lucerne hay & 7.60 & 8.92 \\
\hline Meadow hay & 1.03 & 3.32 \\
\hline Brewer's grains & 7.60 & - \\
\hline Italian ryegrass silage & 11.05 & - \\
\hline Concentrate & 17.62 & 35.27 \\
\hline Whole linseed & 2.60 & 2.16 \\
\hline Crude protein & 16.66 & 16.66 \\
\hline Crude fat & 5.36 & 4.42 \\
\hline NE $_{1}{ }^{1}$ & 179.54 & 177.30 \\
\hline
\end{tabular}

${ }^{1}$ Net energy for lactation (MJ)

The fatty acid composition of the milk fat was determined after precolumn derivatization in the form of fatty acid methyl esters by gascromatography (Varga-Visi and Csapó, 2002).

SPSS for Windows for 22.0 programme was used for the statistical analysis. The data were analyzed by the method of variance (One-way ANOVA). Levene-test was applied to examine homogeneity. Tamhane test (in case of heterogeneity) and the LSD test (in case of homogeneity) were used to compare the group-pairs.

The linear model can be written: 


$$
\chi_{i j}=\mu+\hat{a}_{i}+e_{i j}
$$

where:

$\chi_{i j}$ : is dependable variable (fatty acids),

$\mu$ : overall mean of the observation,

$\dot{a}_{i}$ : effect of treatment factors,

$e_{i j}$ : random element.

Table 2 shows the fatty acid composition of whole linseed and TMR (farm A and B).

Table 2. Fatty acid composition of whole linseed and TMR (A and B farm)

\begin{tabular}{c|c|c|c}
\hline Fatty acids $(\boldsymbol{\%})^{\mathbf{1}}$ & Whole linseed & TMR (A farm) & TMR (B farm) \\
\hline $14: 0^{2}$ & 0.07 & 0.39 & 0.33 \\
\hline $15: 0^{3}$ & 0.02 & 0.07 & 0.05 \\
\hline $16: 0^{4}$ & 5.47 & 20.07 & 18.1 \\
\hline $17: 0^{5}$ & 0.08 & 0.17 & 0.12 \\
\hline $18: 0^{6}$ & 3.01 & 6.50 & 6.19 \\
\hline $20: 0^{7}$ & 0.12 & 0.88 & 1.66 \\
\hline $22: 0^{8}$ & 0.12 & 0.28 & 0.60 \\
\hline $24: 0^{9}$ & 0.09 & 0.28 & 0.60 \\
\hline $16: 1^{10}$ & 0.05 & 0.16 & 0.18 \\
\hline $20: 1^{11}$ & 0.16 & 0.32 & 0.55 \\
\hline $18: 1 \mathrm{n}-9^{12}$ & 18.53 & 20.3 & 36.30 \\
\hline $18: 2 \mathrm{n}-6^{13}$ & 14.96 & 33.70 & - \\
\hline $\mathrm{C} 20: 2^{14}$ & 0.06 & - & 7.12 \\
\hline $18: 3 \mathrm{n}-3^{15}$ & 55.98 & 19.21 & 0.10 \\
\hline $18: 3 \mathrm{n}-6^{16}$ & 0.21 & 0.18 & - \\
\hline $\mathrm{C} 20: 3 \mathrm{n}-6^{17}$ & 0.04 & - & - \\
\hline $\mathrm{C} 20: 4 \mathrm{n}-6^{18}$ & 0.02 & - & - \\
\hline $\mathrm{C} 20: 5^{19}$ & 0.07 & - & $p$ \\
\hline
\end{tabular}

${ }^{1}$ Fatty acid methyl-esters relative $\%$ by weight; ${ }^{2}$ miristic acid; ${ }^{3}$ pentadecylic acid; ${ }^{4}$ palmitic acid; ${ }^{5}$ margaric acid; ${ }^{6}$ stearic acid; ${ }^{7}$ arachidic acid; ${ }^{8}$ behenic acid; ${ }^{9}$ lignoceric acid; ${ }^{10}$ palmitoleic acid;

${ }^{11}$ eicosenoic acid; ${ }^{12}$ oleic acid; ${ }^{13}$ linoleic acid; ${ }^{14}$ eicosadienoic acid; ${ }^{15} \alpha$-linolenic acid; ${ }^{16} \gamma$-linolenic acid,

${ }^{17}$ eicosatrienoic acid; ${ }^{18}$ arachidonic acid; ${ }^{19}$ eicosapentaenoic acid

\section{Results}

Most milk fatty acid proportions of milk samples produced at A and B farms were affected by diets. Table 3 shows the changes in the SFA (saturated fatty acid) composition of milk fat in the experiment period on farm A.

Contents of short $(6: 0,8: 0)$, medium (10:0, 11:0 and 14:0) and long chain fatty acids $(15: 0,17: 0,18: 0,20: 0,21: 0$ and 24:0) were not different after two or four weeks. The contents of 12:0, 16:0, 22:0 and total SFA decreased during the experiment. The 13:0 content increased at the end of the experiment.

The whole linseed supplement affected several MUFA (monounsaturated fatty acid) and PUFA (polyunsaturated fatty acid) contents of milk fat (Table 4.) Feeding whole 
linseed increased the contents of some MUFA (14:1, 18:1 and, 20:1). The total proportion of MUFA increased after two weeks. The proportions of 18:2c9,t11, 18:3n-6, $18: 3 n-3, \quad 20: 5$ and 22:5n-3 increased by the end of experiment. Increasing concentrations of 18:2c9,t11 and 18:3n-3 were pronounced after two weeks by the end of the experiment.

Table 3. The effect of whole linseed on the SFA contents of milk fat (farm A)

\begin{tabular}{c|c|c|c|c}
\hline Fatty acids $(\boldsymbol{\%})^{\mathbf{1}}$ & At the start & After 2 weeks & After 4 weeks & P \\
\hline $6: 0^{2}$ & $0.60 \pm 0.07$ & $0.61 \pm 0.03$ & $0.57 \pm 0.02$ & $\mathrm{~ns}$ \\
\hline $8: 0^{3}$ & $0.56 \pm 0.07$ & $0.52 \pm 0.04$ & $0.55 \pm 0.06$ & $\mathrm{~ns}$ \\
\hline $10: 0^{4}$ & $1.91 \pm 0.41$ & $1.57 \pm 0.28$ & $1.82 \pm 0.34$ & $\mathrm{~ns}$ \\
\hline $11: 0^{5}$ & $0.17 \pm 0.03$ & $0.16 \pm 0.02$ & $0.19 \pm 0.03$ & $\mathrm{~ns}$ \\
\hline $12: 0^{6}$ & $2.92^{\mathrm{a}} \pm 0.66$ & $2.29^{\mathrm{b}} \pm 0.43$ & $2.79^{\mathrm{ab}} \pm 0.63$ & $<0.05$ \\
\hline $13: 0^{7}$ & $0.14^{\mathrm{ab}} \pm 0.03$ & $0.12^{\mathrm{b}} \pm 0.02$ & $0.16^{\mathrm{a}} \pm 0.03$ & $<0.05$ \\
\hline $14: 0^{8}$ & $11.33 \pm 1.21$ & $10.27 \pm 1.37$ & $11.61 \pm 1.36$ & $\mathrm{~ns}$ \\
\hline $15: 0^{9}$ & $1.06 \pm 0.16$ & $1.04 \pm 0.12$ & $1.18 \pm 0.19$ & $\mathrm{~ns}$ \\
\hline $16: 0^{10}$ & $37.55^{\mathrm{a}} \pm 3.30$ & $31.95^{\mathrm{b}} \pm 2.77$ & $33.13^{\mathrm{b}} \pm 2.09$ & $<0.05$ \\
\hline $17: 0^{11}$ & $0.69 \pm 0.08$ & $0.66 \pm 0.06$ & $0.72 \pm 0.06$ & $\mathrm{~ns}$ \\
\hline $18: 0^{12}$ & $13.31 \pm 1.40$ & $14.09 \pm 1.49$ & $12.56 \pm 2.01$ & $\mathrm{~ns}$ \\
\hline $20: 0^{13}$ & $0.19 \pm 0.03$ & $0.17 \pm 0.01$ & $0.18 \pm 0.03$ & $\mathrm{~ns}$ \\
\hline $21: 0^{14}$ & $0.03 \pm 0.01$ & $0.03 \pm 0.01$ & $0.03 \pm 0.01$ & $\mathrm{~ns}$ \\
\hline $22: 0^{15}$ & $0.09^{\mathrm{a}} \pm 0.01$ & $0.07^{\mathrm{b}} \pm 0.01$ & $0.07^{\mathrm{b}} \pm 0.01$ & $<0.05$ \\
\hline $24: 0^{16}$ & $0.05 \pm 0.01$ & $0.04 \pm 0.01$ & $0.04 \pm 0.01$ & $\mathrm{~ns}$ \\
\hline$\Sigma \mathrm{SFA}^{17}$ & $70.60^{\mathrm{a}} \pm 3.95$ & $63.59^{\mathrm{b}} \pm 4.10$ & $65.60^{\mathrm{b}} \pm 3.71$ & $<0.05$ \\
\hline & & & & \\
\hline
\end{tabular}

${ }^{1}$ Fatty acid methyl-esters relative \% by weight; ${ }^{2}$ caproic acid; ${ }^{3}$ caprycil acid; ${ }^{4}$ capric acid; ${ }^{5}$ undecylenic acid; ${ }^{6}$ lauric acid; ${ }^{7}$ trydecylic acid; ${ }^{8}$ myristic acid; ${ }^{9}$ pentadecylic acid; ${ }^{10}$ palmitic acid; ${ }^{11}$ margaric acid; ${ }^{12}$ stearic acid; ${ }^{13}$ arachidic acid; ${ }^{14}$ heneicosylic acid; ${ }^{15}$ behenic acid; ${ }^{16}$ lignoceric acid; ${ }^{17} \Sigma$ saturated fatty acid The averages marked with different letters within the same lines are significantly different from each other at $\mathrm{P}<0.05$

Table 4. The effect of whole linseed on the MUFA and the PUFA contents of milk fat (farm A)

\begin{tabular}{c|c|c|c|c}
\hline${\text { Fatty acids }(\boldsymbol{\%})^{\mathbf{1}}}$ & At the start & After 2 weeks & After 4 weeks & P \\
\hline $14: 1^{2}$ & $0.73^{\mathrm{b}} \pm 0.15$ & $0.82^{\mathrm{ab}} \pm 0.15$ & $0.99^{\mathrm{a}} \pm 0.22$ & $<0.05$ \\
\hline $16: 1^{3}$ & $1.40 \pm 0.32$ & $1.51 \pm 0.25$ & $1.57 \pm 0.36$ & $\mathrm{~ns}$ \\
\hline $18: 1 \mathrm{t}^{4}$ & $1.41 \pm 0.48$ & $1.60 \pm 0.41$ & $1.28 \pm 0.35$ & $\mathrm{~ns}$ \\
\hline $18: 1 \mathrm{c}^{5}$ & $20.77^{\mathrm{b}} \pm 2.76$ & $27.08^{\mathrm{a}} \pm 3.37$ & $25.50^{\mathrm{a}} \pm 2.91$ & $<0.05$ \\
\hline $20: 1^{6}$ & $0.04^{\mathrm{b}} \pm 0.01$ & $0.05^{\mathrm{a}} \pm 0.01$ & $0.05^{\mathrm{a}} \pm 0.01$ & $<0.05$ \\
\hline$\Sigma M \mathrm{MFA}^{7}$ & $24.53^{\mathrm{b}} \pm 8.19$ & $31.28^{\mathrm{a}} \pm 10.07$ & $29.61^{\mathrm{a}} \pm 10.13$ & $<0.05$ \\
\hline $18: 2^{8}$ & $2.70 \pm 0.49$ & $2.56 \pm 0.43$ & $2.43 \pm 0.35$ & $\mathrm{~ns}$ \\
\hline $18: 2 \mathrm{c} 9 \mathrm{t} 11^{9}$ & $0.30^{\mathrm{c}} \pm 0.04$ & $0.46^{\mathrm{a}} \pm 0.07$ & $0.38^{\mathrm{b}} \pm 0.06$ & $<0.05$ \\
\hline $18: 3 \mathrm{n}-6^{10}$ & $0.04^{\mathrm{b}} \pm 0.01$ & $0.04^{\mathrm{b}} \pm 0.01$ & $0.06^{\mathrm{a}} \pm 0.01$ & $<0.05$ \\
\hline $18: 3 \mathrm{n}-3^{11}$ & $0.34^{\mathrm{c}} \pm 0.05$ & $0.60^{\mathrm{a}} \pm 0.01$ & $0.42^{\mathrm{b}} \pm 0.06$ & $<0.05$ \\
\hline $20: 2^{12}$ & $0.02^{2} \pm 0.005$ & $0.02 \pm 0.01$ & $0.02 \pm 0.007$ & $\mathrm{~ns}$ \\
\hline $20: 3^{13}$ & $0.14^{\mathrm{a}} \pm 0.04$ & $0.08^{\mathrm{b}} \pm 0.02$ & $0.10^{\mathrm{ab}} \pm 0.05$ & $<0.05$ \\
\hline $20: 4 \mathrm{n}-6^{14}$ & $0.20^{\mathrm{a}} \pm 0.04$ & $0.16^{\mathrm{b}} \pm 0.02$ & $0.16^{\mathrm{b}} \pm 0.02$ & $<0.05$
\end{tabular}




\begin{tabular}{c|c|c|c|c}
\hline $20: 5 \mathrm{n}-3^{15}$ & $0.03^{\mathrm{b}} \pm 0.07$ & $0.04^{\mathrm{a}} \pm 0.008$ & $0.04^{\mathrm{a}} \pm 0.008$ & $<0.05$ \\
\hline $22: 5 \mathrm{n}-3^{16}$ & $0.07^{\mathrm{b}} \pm 0.01$ & $0.07^{\mathrm{b}} \pm 0.01$ & $0.08^{\mathrm{a}} \pm 0.008$ & $<0.05$ \\
\hline$\Sigma \mathrm{PUFA}^{17}$ & $3.82^{\mathrm{ab}} \pm 1.35$ & $4.02^{\mathrm{a}} \pm 1.37$ & $3.65^{\mathrm{ab}} \pm 1.26$ & $<0.05$ \\
\hline$\Sigma \mathrm{n}-6$ & 3.08 & 2.84 & 2.75 & $\mathrm{~ns}$ \\
\hline$\Sigma \mathrm{n}-3$ & 0.44 & 0.71 & 0.54 & $\mathrm{~ns}$ \\
\hline $\mathrm{n}-6 / \mathrm{n}-3$ & 7.00 & 4.00 & 5.09 & $\mathrm{~ns}$ \\
\hline
\end{tabular}

${ }^{1}$ Fatty acid methyl-esters relative $\%$ by weight; ${ }^{2}$ myristoleic acid; ${ }^{3}$ palmitoleic acid; ${ }^{4}$ elaidic acid; ${ }^{5}$; oleic acid; ${ }^{6}$ eicosenoic acid; ${ }^{7}$ Dmonounsaturated acid; ${ }^{8}$ linoleic acid; ${ }^{9}$ conjugated linoleic acid; ${ }^{10} \gamma$-linolenic acid; ${ }^{11} \alpha$-linolenic acid; ${ }^{12}$ eicosadienoic acid; ${ }^{13}$ eicosatrienoic acid; ${ }^{14}$ arachidonic acid; ${ }^{15}$ eicosapentaenoic acid; ${ }^{16}$ docosapentaenoic acid; ${ }^{17} \Sigma$ polyunsaturated fatty acid

The averages marked with different letters within the same lines are significantly different from each other at $\mathrm{P}<0.05$

Our study showed that the whole linseed supplementation decreased the $n-6$ fatty acid contents and increased the n-3 fatty acid contents, however the n-6/n-3 ratio narrowed, but this result was not significant.

Table 5 shows the SFA contents of milk samples produced on farm B. Whole linseed had no effect on proportions of 6:0, 8:0, 10:0, 11:0, 14:0, and 24:0. The proportions of 12:0, 13:0, 15:0 and 17:0 decreased after two weeks. The 16:0 increased by the end of the experiment. During of the experiment no proven changes were observed in the total SFA contents of milk samples.

Table 5. The effect of whole linseed on the SFA contents of milk fat (farm B)

\begin{tabular}{c|c|c|c|c}
\hline Fatty acids $(\boldsymbol{\%})^{\mathbf{1}}$ & At the start & After 2 weeks & After 4 weeks & P \\
\hline $6: 0^{2}$ & $0.62 \pm 0.11$ & $0.67 \pm 0.06$ & $0.67 \pm 0.08$ & $\mathrm{~ns}$ \\
\hline $8: 0^{3}$ & $0.60 \pm 0.13$ & $0.59 \pm 0.08$ & $0.59 \pm 0.08$ & $\mathrm{~ns}$ \\
\hline $10: 0^{4}$ & $2.21 \pm 0.61$ & $1.87 \pm 0.35$ & $1.98 \pm 0.40$ & $\mathrm{~ns}$ \\
\hline $11: 0^{5}$ & $0.25 \pm 0.08$ & $0.20 \pm 0.04$ & $0.22 \pm 0.06$ & $\mathrm{~ns}$ \\
\hline $12: 0^{6}$ & $3.45^{\mathrm{a}} \pm 0.98$ & $2.75^{\mathrm{b}} \pm 0.54$ & $2.94^{\mathrm{b}} \pm 0.62$ & $<0.05$ \\
\hline $13: 0^{7}$ & $0.25^{\mathrm{a}} \pm 0.09$ & $0.13^{\mathrm{b}} \pm 0.03$ & $0.15^{\mathrm{b}} \pm 0.04$ & $<0.05$ \\
\hline $14: 0^{8}$ & $11.54 \pm 1.29$ & $11.19 \pm 1.00$ & $11.76 \pm 1.06$ & $\mathrm{~ns}$ \\
\hline $15: 0^{9}$ & $1.56^{\mathrm{a}} \pm 0.46$ & $0.98^{\mathrm{b}} \pm 0.11$ & $1.05^{\mathrm{b}} \pm 0.15$ & $<0.05$ \\
\hline $16: 0^{10}$ & $36.51^{\mathrm{ab}} \pm 2.88$ & $34.18^{\mathrm{b}} \pm 3.06$ & $37.45^{\mathrm{a}} \pm 3.57$ & $<0.05$ \\
\hline $17: 0^{11}$ & $0.77^{\mathrm{a}} \pm 0.10$ & $0.61^{\mathrm{b}} \pm 0.06$ & $0.59^{\mathrm{b}} \pm 0.06$ & $<0.05$ \\
\hline $18: 0^{12}$ & $10.13^{\mathrm{b}} \pm 2.17$ & $12.79^{\mathrm{a}} \pm 1.83$ & $10.78^{\mathrm{ab}} \pm 3.09$ & $<0.05$ \\
\hline $20: 0^{13}$ & $0.13^{\mathrm{ab}} \pm 0.03$ & $0.15^{\mathrm{a}} \pm 0.02$ & $0.12^{\mathrm{b}} \pm 0.04$ & $<0.05$ \\
\hline $21: 0^{14}$ & $0.03^{\mathrm{a}} \pm 0.01$ & $0.03^{\mathrm{a}} \pm 0.01$ & $0.02^{\mathrm{b}} \pm 0.01$ & $<0.05$ \\
\hline $22: 0^{15}$ & $0.06^{\mathrm{ab}} \pm 0.02$ & $0.07^{\mathrm{a}} \pm 0.01$ & $0.05^{\mathrm{b}} \pm 0.01$ & $<0.05$ \\
\hline $24: 0^{16}$ & $0.04 \pm 0.01$ & $0.06 \pm 0.06$ & $0.04 \pm 0.06$ & $\mathrm{~ns}$ \\
\hline$\Sigma \mathrm{SFA}^{17}$ & $68.14 \pm 9.56$ & $66.28 \pm 9.17$ & $68.56 \pm 9.39$ & $\mathrm{~ns}$ \\
\hline
\end{tabular}

${ }^{1}$ Fatty acid methyl-esters relative $\%$ by weight; ${ }^{2}$ caproic acid; ${ }^{3}$ caprycil acid; ${ }^{4}$ capric acid; ${ }^{5}$ undecylenic acid; ${ }^{6}$ lauric acid; ${ }^{7}$ trydecylic acid; ${ }^{8}$ myristic acid; ${ }^{9}$ pentadecylic acid; ${ }^{10}$ palmitic acid; ${ }^{11}$ margaric acid; ${ }^{12}$ stearic acid; ${ }^{13}$ arachidic acid; ${ }^{14}$ heneicosylic acid; ${ }^{15}$ behenic acid; ${ }^{16}$ lignoceric acid; ${ }^{17} \Sigma$ saturated fatty acid The averages marked with different letters within the same lines are significantly different from each other at $\mathrm{P}<0.05$ 
The whole linseed supplement decreased the concentrations of some MUFA (18:11, 20:1) and PUFA (18:2, 18:3n-6, 20:3, 20:4) during the experiment (Table 6.). The proportion of long-chain PUFA, such as 18:1c, 18:3n-3, 20:5 and 22:5n-3 were higher in the milk fat during the experiment. The whole linseed supplement had no effect on total MUFA, however the total proportion of PUFA decreased after four weeks.

In the present study, the whole linseed supplementation decreased the $n-6$ fatty acid contents and increased the n-3 fatty acids contents, however the $n-6 / n-3$ ratio was favourable, but this result was not significant.

Table 6. The effect of whole linseed on the MUFA and the PUFA contents of milk fat (farm B)

\begin{tabular}{c|c|c|c|c}
\hline Fatty acids $(\boldsymbol{\%})^{\mathbf{1}}$ & At the start & After 2 weeks & After 4 weeks & P \\
\hline $14: 1^{2}$ & $0.85 \pm 0.27$ & $0.88 \pm 0.24$ & $0.97 \pm 0.33$ & $\mathrm{~ns}$ \\
\hline $16: 1^{3}$ & $1.78 \pm 0.37$ & $1.52 \pm 0.38$ & $1.82 \pm 0.55$ & $\mathrm{~ns}$ \\
\hline $18: 1 \mathrm{t}^{4}$ & $2.39^{\mathrm{a}} \pm 0.96$ & $1.57^{\mathrm{b}} \pm 0.23$ & $1.40^{\mathrm{b}} \pm 0.28$ & $<0.05$ \\
\hline $18: 1 \mathrm{c}^{5}$ & $21.33^{\mathrm{b}} \pm 3.36$ & $24.71^{\mathrm{a}} \pm 2.96$ & $22.51^{\mathrm{ab}} \pm 2.88$ & $<0.05$ \\
\hline $20: 1^{6}$ & $0.05^{\mathrm{a}} \pm 0.01$ & $0.05^{\mathrm{a}} \pm 0.01$ & $0.04^{\mathrm{b}} \pm 0.004$ & $<0.05$ \\
\hline$\Sigma \mathrm{MUFA}^{7}$ & $26.60 \pm 8.33$ & $28.89 \pm 9.77$ & $26.75 \pm 8.76$ & $\mathrm{~ns}$ \\
\hline $18: 2^{8}$ & $3.19^{\mathrm{a}} \pm 0.28$ & $2.36^{\mathrm{b}} \pm 0.25$ & $2.28^{\mathrm{b}} \pm 0.22$ & $<0.05$ \\
\hline $18: 2 \mathrm{c} 9 \mathrm{t} 11^{9}$ & $0.45 \pm 0.08$ & $0.48 \pm 0.06$ & $0.45 \pm 0.11$ & $\mathrm{~ns}$ \\
\hline $18: 3 \mathrm{n}-6^{10}$ & $0.4^{\mathrm{a}} \pm 0.01$ & $0.03^{\mathrm{b}} \pm 0.006$ & $0.03^{\mathrm{b}} \pm 0.006$ & $<0.05$ \\
\hline $18: 3 \mathrm{n}-3^{11}$ & $0.23^{\mathrm{b}} \pm 0.02$ & $0.58^{\mathrm{a}} \pm 0.07$ & $0.59^{\mathrm{a}} \pm 0.11$ & $<0.05$ \\
\hline $20: 2^{12}$ & $0.02^{12} \pm 0.01$ & $0.02 \pm 0.01$ & $0.03 \pm 0.04$ & $\mathrm{~ns}$ \\
\hline $20: 3^{13}$ & $0.13^{\mathrm{a}} \pm 0.03$ & $0.08^{\mathrm{b}} \pm 0.02$ & $0.07^{\mathrm{b}} \pm 0.02$ & $<0.05$ \\
\hline $20: 4 \mathrm{n}-6^{14}$ & $0.20^{\mathrm{a}} \pm 0.03$ & $0.14^{\mathrm{b}} \pm 0.02$ & $0.13^{\mathrm{b}} \pm 0.02$ & $<0.05$ \\
\hline $20: 5 \mathrm{n}-3^{15}$ & $0.01^{\mathrm{b}} \pm 0.005$ & $0.03^{\mathrm{a}} \pm 0.01$ & $0.03^{\mathrm{a}} \pm 0.01$ & $<0.05$ \\
\hline $22: 5 \mathrm{n}-3^{16}$ & $0.05^{\mathrm{b}} \pm 0.01$ & $0.07^{\mathrm{a}} \pm 0.01$ & $0.06^{\mathrm{ab}} \pm 0.01$ & $<0.05$ \\
\hline$\Sigma \mathrm{PUFA}$ & $4.33^{\mathrm{a}} \pm 1.56$ & $3.79^{\mathrm{b}} \pm 1.28$ & $3.69^{\mathrm{b}} \pm 1.25$ & $<0.05$ \\
\hline$\Sigma \mathrm{n}-6$ & 3.92 & 2.61 & 2.51 & $\mathrm{~ns}$ \\
\hline$\Sigma \mathrm{n}-3$ & 0.29 & 0.68 & 0.68 & $\mathrm{~ns}$ \\
\hline $\mathrm{n}-6 / \mathrm{n}-3$ & 13.52 & 3.83 & 3.69 & $\mathrm{~ns}$ \\
\hline
\end{tabular}

${ }^{1}$ Fatty acid methyl-esters relative $\%$ by weight; ${ }^{2}$ myristoleic acid; ${ }^{3}$ palmitoleic acid; ${ }^{4}$ elaidic acid; ${ }^{5}$; oleic acid; ${ }^{6}$ eicosenoic acid; ${ }^{7}$ Lmonounsaturated acid; ${ }^{8}$ linoleic acid; ${ }^{9}$ conjugated linoleic acid; ${ }^{10} \gamma$-linolenic acid; ${ }^{11} \quad \alpha$-linolenic acid; ${ }^{12}$ eicosadienoic acid; ${ }^{13}$ eicosatrienoic acid; ${ }^{14}$ arachidonic acid; ${ }^{15}$ eicosapentaenoic acid; ${ }^{16}$ docosapentaenoic acid; ${ }^{17}$ Dpolyunsaturated fatty acid

The averages marked with different letters within the same lines are significantly different from each other at $\mathrm{P}<0.05$

\section{Discussion}

One of numerous possible ways to increase the proportion of PUFA and decrease the proportion of SFA of milk fat is to use linseed. According to Ferlay et al. (2013) and Hurtaud et al. (2010) the extruded linseed in increasing amount of supplementation is suitable to increase the content of n-3 series FA in milk fat, while in Saliba et al.'s (2014) opinion the linseed oil can enhance the content of $\alpha$-linolenic acid of milk fat. Lerch et al. (2015) found that extruded linseed supplementation increased the PUFA content of milk fat, and did not induce oxidised off-flavours in milk or cheese. 
In contrast, according to Kennelly (1996) feeding PUFA, which is protected against ruminal biohydrogenation, increases their proportion in milk. The hard seedcoat of whole linseed may effectively protect alpha-linoleic acid from ruminal biohydrogenation (Givens et al., 2009; Oba et al., 2009).

In our experiment, the dietary application had a significant impact on the proportion of several milk fatty acids on both farms. Whole linseed had influences on SFA, MUFA acid content of milk fat different levels. In general, on both farms, the dietary supplementation of whole linseed depressed $(\mathrm{P}<0.05)$ several medium-chain SFA and increased $(\mathrm{P}<0.05)$ some long-chain PUFA, especially alpha-linolenic acid in milk fat. Content of short-chain fatty acids in milk fat was not affected by dietary supplementation of whole linseed at each of farms.

Our results showed that the decreasing proportion of several saturated fatty acids were in correspondence with other research data (Precht and Molkentin, 2000; Chilliard et al., 2001). The decreasing tendency of SFA content - explained in the literature by de novo milk fat synthesis remission - was found in some researches, in which different protected fats and oil seeds were used (Dhiman et al., 1999; Precht and Molkentin, 2000; Chilliard et al., 2001; Petit and Gagnon, 2009).

The 18:1 (oleic acid) content increased on both farms. This finding is in line with the report of Ward et al. (2002), who found similar tendency with different oilseeds.

Reviewing data of MUFA and PUFA from whole linseed feed supplement we found that, in accordance with our theory, the biggest differences were observed in the proportion of $\alpha$-linoleic acid on both farms. The proportion of $\alpha$-linoleic acid doubled during the experiment on both farms. Our results are in accordance with those of Gandra et al. (2016).

Others reported an increase in the concentration of very long-chain polyunsaturated fatty acids like 20:5n-3 and 22:5n-3, as a result of feeding different forms of linseed (Hagemeister et al., 2001). In our experiment, concentrations of 20:5n-3 and 22:5n-3 were increased by whole linseed supplementation.

Despite the increase in the proportion of health-promoting milk fatty acids such as $18: 3 n-3$ as a result of whole linseed supplementation, the levels of these fatty acids remained under $1 \%$ of total milk fatty acids. These findings suggest extensive ruminal biohydrogenation of dietary PUFA. In our experiment feeding whole linseed resulted in a bigger $n-3$ ratio in milk fat on both farms, the ratio of $n-6 / n-3$ narrowed during the experiment on both farms, but these results were not significant. This agrees with Petit (2002) who reported a decrease in the n-6 to n-3 fatty acid ratio when cows were fed whole linseed compared with micronized soybeans or calcium salts of palm oil.

\section{Conclusions}

Nutrition can be regarded as one of the most important source of variation composition of milk fat. The fatty acid composition of oilseeds such as full fat linseed is considered desirable for human health and thus their inclusion in the diet of dairy cattle is important as a means of achieving a more desirable fatty acid profile in milk fat. The results of the present study demonstrated that oilseeds, especially whole linseed, are easy to fit into feeding systems of intensive dairies in Hungary, too. Feeding dairy cows a diet with whole linseed decreased the proportion of several SFA and increased the proportion of some MUFA and PUFA, especially C18:3n-3. The $2.60 \%$ whole linseed supplementation of the daily ration narrowed the $n-6 / n-3$ ratio on farm $A$, while the 
2.16\% whole linseed supplementation of the daily ration narrowed it on farm B, but these results were not significant. More research is needed on dairy farms in Hungary to use other supplements to increase the n-3 concentration in milk fat because of the composition of milk fat is important for dairy industry and human health and it is related to milk quality.

\section{REFERENCES}

[1] Caroprese, M., Mancinoc, R., Ciliberti, M. G., DiLuccia, A., LaGatta, B., Albenzio, M. (2017): Fatty acid profile and coagulating ability of milk from Jersey and Frieasien cows fed whole flaxseed. - Journal of Dairy Research 84(1): 14-22.

[2] Chilliard, Y., Ferlay, A., Doreau, A. (2001): Effect of different types of forages, animal fat or marine oils in cow's diet on milk fat secretion and composition, especially conjugated linoleic acid (CLA) and polyunsaturated faty acid. - Livestock Production Science 70(1-2): 31-48.

[3] Demeyer, D., Doreau, M. (1999): Targets and procedures for alter in ruminant meat and milk lipids. - Proceedings of Nutrition Society 58(3): 593-607.

[4] Dhiman, T. R., Anand, G. R., Satter, L. D., Pariza, M. W. (1999): Conjugated linoleic acid content of milk from cows fed different diets. - Journal od Dairy Science 82(10): 2146-2146.

[5] Elgersma, A., Tamminga, S., Ellen, G. (2006): Modifying milk composition through forage. - Animal Feed Science Technology 131(3-4): 207-225.

[6] Ferlay, A., Doreau, M., Martin, C., Chilliard, Y. (2013): Effect of incremental amounts of extruded linseed on the milk fatty acid composition of dairy cows receiving hay or corn silage. - Journal of Dairy Science 96(10): 6577-6595.

[7] Gandra, J. R., Mingoti, R. D., Barletta, R. V., Takiya, C. S., Verdurico, L. C., Freitas, J. E., Paiva, P. G., Jesus, E. F., Calomeni, G. D., Renno, F. P. (2016): Effect of flaxseed, raws soybeans and calcium salts of fatty acids on apparent total tract digestibility, energy balance and milk fatty acid profile of transition cows. - Animal 10(8): 1303-1310.

[8] Givens, D. I., Kliem, K. E., Humphries, D. J., Shingfield, K. J. (2009): Effect of replacing calcium salts of palm oil distillate with rapeseed oil, milled or whole rapeseeds on milk fatty acid composition in cows fed maize silage-based diets. - Animal 3(7): 1067-1074.

[9] Hagemeister, H., Franzen, M., Barth, C. A., Precht, D. (2001): $\alpha$-linolenic acid transfer into milk fat and its elongation by cows. - European Journal of Lipid Science Technology 93(10): 387-391.

[10] Halasz, A., Nagy, G., Tasi, J., Bajnok, M., Mikone, J. E. (2016): Weather regulated cattle behaviour on rangeland. - Applied Ecology and Environmental Research 14(4): 149-158.

[11] Hurtaud, C., Faucon, F., Couvreur, S., Payraud, J.-L. (2010): Linear relationship between increasing amounts of extruded linseed in dairy cow diet and milk fatty acid composition and butter properties. - Journal of Dairy Science 93(4): 1429-1443.

[12] Kennelly, J. J. (1996): The fatty acid composition of milk fat as influenced by feeding oilseed. - Animal Feed Science and Technology 60(3-4): 137-152.

[13] Kinsella, J. E. (1991): $\alpha$-Linolenic Acid Functions and Effects on Linoleic Acid Metabolism and Eicosanoid-Mediated Reactions. - In: Kinsella, J. E. (ed.) Advances in Food and Nutrition Research. Academic Press, Cambridge.

[14] Lerch, S., Ferlay, A., Graulet, B., Cirié, C., Verdier-Metz, I., Montel, M. C., Chilliard, Y., Martin, B. (2015): Extruded linseeds, vitamin E and plant extracts in corn silage-based diets of dairy cows: Effect on sensory properties of raw milk and uncooked pressed cheese. - International Dairy Journal. 51: 65-74.

[15] Livingstone, K. M., Humphries, D. J., Kliem, K. E., Givens, D. I., Reynolds, C. K. (2015): Effects of forage type and extruded linseed supplementation on methane 
production and milk fatty acid composition of lactating dairy cows. - Journal of Dairy Science 98(6): 4000-4011.

[16] Moallem, U. (2009): The effects of extruded flaxseed supplementation to high-yielding dairy cows on milk production and milk faty acid composition. - Animal Feed Science and Technology 152(3-4): 232-242.

[17] Murphy, J. J., Conolly, J. F., Mcneil, G. P. (1995a): Effects on milk fat composition and cow performance of feeding concentrates containing full fat rapeseed and maize distillers grains on grass-silage based diets. - Livestock Production Science 44(1): 1-11.

[18] Murphy, J. J., Conolly, J. F., Mcneil, G. P. (1995b): Effects of performance and milk fat composition of feeding full fat soyabeans and rapeseeds to dairy cows at pasture. Livestock Production Science 44(1): 13-25.

[19] Oba, M., Thangavelu, G., Dehghan-Banadaky, M., Ambrose, D. J. (2009): Unprocessed whole flaxseed is as effective as dry-rolled flaxseed at increasing $\alpha$-linolenic concentration in milk of dairy cows. - Livestock Science 122(1): 73-76.

[20] Peredi, J. (2002): A hazai lakosság alacsony n-3 zsírsavelláottságának javítási lehetőségei. - Olaj, Szappan, Kozmetika 51(2): 45-49.

[21] Petit, H. V. (2002): Digestion, milk production, milk composition and blood composition of dairy cows fed whole flaxseed. - Journal of Dairy Science 85(6): 1482-1490.

[22] Petit, H. V. (2003): Digestion, milk production, milk composition and blood composition of daiy cows fed formaldehyde treated flaxseed or sunflower seed. - Journal of Dairy Science 86(8): 2637-2646.

[23] Petit, H. V., Gagnon, N. (2009): Milk concentrations of the mammalian lignans enterolactone and enterodiol, milk production and whole tract digestibility of dairy cows fed diets containing different concentrations of flaxseed meal. - Animal Feed Science and Technology 152(1-2): 103-111.

[24] Poti, P., Pajor, F., Bodnar, A., Penksza, K., Koles, P. (2015): Effect of micro-alga supplementation on goat and cow milk fatty acid composition. - Chilean Journal of Agricultural Research 75(2): 259-263.

[25] Precht, D., Molkentin, J. (2000): Frequency distributions of onjugated linoleic acid and trans fatty acid content in European bovine milk fats. - Milchwissensaft 55(12): 687-691.

[26] Saliba, L., Gervais, R., Lebeuf, Y., Vuillemard, J.-C., Fortin, J., Chouinard, P. Y. (2014): Effect of feeding linseed oil in diets differing in forage to concentrate ratio: 2. Milk lactone profile. - Journal of Dairy Research. 81(1): 91-97.

[27] Simopoulus, A. P. (1999): Essential fatty acids in health and chronic disease. - The American Journal of Clinical Nutrition 70(3): 560-569.

[28] Simopoulus, A. P. (2001): n-3 fatty acids and human health: Defining strategies for public policy. - Lipids 36(1): S83-S89.

[29] Varga-Visi, E., Csapó, J. (2002): Illózsírsavak, zsírsavak és koleszterin tartalom meghatározása gázkromatográffal a Kaposvári Egyetem Állattudományi Karának Kémiai Intézetében. - In: Varga-Visi, E., Csapó, J. (eds.) Proceedings of Scientific Meeting of the Chemical Institutes. University of West Hungary, Sopron.

[30] Ward, A. T., Wittenberg, K. M., Przybylski, R. (2002): Bovine milk fatty acid profiles produced by feeding diets containing solin, flay and canola. - Journal of Dairy Science 85(5): 1191-1196.

[31] White, S. L., Bertrand, J. A., Wade, M. R., Washburn, S. P., Green, J. T., Jenkins, T. C. (2001): Comparison of fatty acid content of milk from Jersey and Holstein cows consuming pasture or total mixed ration. - Journal of Dairy Science 84(10): 2294-2301. 